\title{
Peace and War with Endogenous State Capacity
}

Michael McBride

Department of Economics

University of California, Irvine

Gary Milante

The World Bank

and

Stergios Skaperdas

Department of Economics

University of California, Irvine

September 22, 2009

Abstract: We explore how peace or war can occur in the presence of commitment problems. These problems can be reduced by institutions of good governance or, alternatively, state capacity which (i) can be considered a collective good and (ii) can be improved through investments. We show how the likelihood of a peace agreement depends on the level of state capacity and on investments in state capacity made by adversaries. In accordance with existing evidence but contrary to various theories of conflict, we find that income levels unambiguously increase the chance of peace. Among other issues, we discuss the critical role of external actors in encouraging or discouraging commitment and in developing good governance institutions. 


\section{Introduction}

Civil wars and other internal conflicts typically take long to resolve. For instance, the median length of a civil war in the post-World War II period has been more than seven years and persistence has been high as well (Collier et. al., 2003, p.80). Why wars last for as long as they do is akin to asking why conflict occurs in the first place. Answers that have been proposed in the literature include incomplete or asymmetric information; indivisibilities or increasing returns on matters of contention; risk-seeking behavior; hate, revenge, and other preferential externalities; excessive optimism and wrong mental models of the world; and incomplete contracting or commitment difficulties. ${ }^{1}$

Not all reasons for conflict are as important at the end of conflict as at the start. As conflicts drag out over months and years, adversaries' incomplete information can be expected to subside, as should excessive optimism or incorrect mental models of the conflict. In some cases, indivisibilities can persist reducing the contracting space for peace agreements to nothing. Additionally, it is possible that hate and the urge for revenge could increase with time, fatalities, and atrocities and thus complicate a conflict's ending. One persistent reason, however, that can cause conflict and perpetuate it is difficulties with trust or the absence of sufficient external enforcement in making adversaries abide by a peace agreement. That is, to phrase it differently, contracts on arming are difficult and costly to enforce and commitments to specific levels of arming can be difficult to implement. ${ }^{2}$

However, the modeling choice is not just between perfect commitment and its complete absence. Between the two extremes of the philosopher's state of nature (where there is no possibility of commitment) on the one hand, and

\footnotetext{
${ }^{1}$ For overviews of explanations of conflict see Fearon (1995), Hirshleifer (1995), and Skaperdas (2006). For overviews of the economics of conflict and the literature on civil wars, respectively, see Garfinkel and Skaperdas (2007) and Blattman and Miguel (2009). A thoughtful discussion on how these models pertain to the sustainability of post-conflict peace can be found in Cunningham (2006).

${ }^{2}$ Fearon (1995) first discussed the ideas associated with the problems of incomplete contracting, and dynamic models of the problem include Garfinkel and Skaperdas (2000) and Powell (2006). These enforcement issues as discussed specifically in the context of peace agreements are further developed in Werner and Yen (2005).

The first part of our model (on the choice between conflict and peace) is based on McBride and Skaperdas $(2007,2009)$, whereas the second part of the model (on investments in conflict management) is party inspired by Genicot and Skaperdas (2002). Kumar (2008) also examines a dynamic model of growth that incorporates investment in property rights.
} 
economic models in which property rights are perfectly and costlessly enforced (so that commitment is perfect and costless) on the other hand, there is a broad spectrum of commitment space which defines the agreements that can be reached and which agreements are not credible. Adversaries are typically able to make some limited commitments using third parties, social and political institutions that they have inherited from the past, or elements of the state that might have the independence and strength to partially guarantee peace agreements. That is, commitment problems can be thought to depend on a type of collective good that can be variously attributed to governance, institutions, trust, social capital or bridging capital, property rights, or state capacity, the last term being the one we will be mostly using in this paper. With time, the adversaries themselves could engage in actions that enhance their collective ability to commit. Instances of such actions range from the hiring of a (limited) external enforcer, the podesta, by rival clans in late Medieval Genoa (Greif, 1998) to the often drawn-out negotiations, confidence-building measures, and state-building that adversaries have engaged in more recent times. ${ }^{3}$

We first explore the factors that determine whether peace or conflict will prevail for a given, exogenous level of state capacity. Given a certain level of arming, each adversary compares expected payoffs from conflict against those of a peace agreement. Conflict has costs that may involve destruction and additional use of resources, but provides the chance of being in a better strategic position in the future and having to spend less on arming in order to maintain such a position. Peace avoids the current costs of conflict but requires, because of commitment problems, the continued maintenance of some level of arming in order to have the bargaining position that will allow the peace agreement to be self-enforcing. The higher the level of commitment, induced by greater state capacity, the lower is the level of arming that each side would have to maintain in order to self-enforce peace.

\footnotetext{
${ }^{3}$ Credible, neutral and respected peacekeepers, mediators and observers from international and regional institutions can also fill the gap, creating commitment space for otherwise untenable agreements. We caution, though, that just as NGOs providing humanitarian aid can supplant local capacity to deliver social services, so too can international peacekeeping contribute to peace through building commitment space that does not reflect actual state capacity for commitments. Policymakers must ask, when peacekeepers leave, what state capacity has been built in country to deliver this commitment space? For more on the importance of aligning political missions and state capacity building to peacekeeping missions for success in peacebuilding, see Doyle and Sambanis (2000).
} 
Peace becomes possible only when all parties to the agreement prefer it to continued conflict, and that is possible when state capacity is above a critical threshold. The threshold level itself depends on the destruction and other possible extra costs of conflict but also on the discount factor, the shadow of the future. In particular, the effect of a longer shadow of the future tends to be a detriment to peace in the sense that state capacity's critical threshold becomes higher the higher is the discount factor.

We next explore the determinants of state capacity. In section 3 we consider three factors that could affect the degree of commitment through state capacity. First, outside forces can intervene for good (third parties genuinely interested in peace) or bad (third parties that have an interest in the continuation in conflict or are biased toward changing the terms of an eventual peace in favor of one of the adversaries). Second, the degree of commitment depends on the history of interaction among the parties, with a longer history of conflict, mutual isolation, and distrust reducing the capacity for commitment. Finally, the adversaries themselves can engage in investments that improve state capacity for commitments.

In section 4 we extend our model to consider the first and last factors. In this environment, adversaries will undertake positive levels of investment in state capacity only when they expect to induce peace, although they will also engage in some arming given that commitment is not typically perfect in equilibrium. In this respect, our model captures the truly ambivalent nature of peace negotiations, where the actors grip the olive branch in one hand and the sword in the other. When the adversaries expect war, there is no reason to invest in state capacity, and they instead concentrate all of their resources on arming to enhance their probability of winning, confirming that investments in state capacity for commitments can serve as credible signals of actors' belief in peace. Whereas the levels of investment in state capacity in equilibrium are unique, those are not necessarily the only levels of investment that might be expected to occur. It would be generally in the collective interest of both parties to engage in investments that are higher than those that would occur in equilibrium and if the parties could coordinate on higher levels they might be able to do so. The ability to coordinate on and implement such investments may well be a key factor for some countries in maintaining peace. 
Another notable effect we find is that an increase in the value of the "prize" that is the object of contention between adversaries unambiguously increases investments in state capacity (except when these investments are already zero) and thus unambiguously enhances the payoffs under peace. If the value of the prize and income are correlated, then this result implies that we would expect higher income countries to have both higher state capacity and better prospects of peace, whereas lower income countries would tend to have lower levels of state capacity and more fighting. This is in line with the correlations observed (Collier

et. al., 2003) but also with the attempts to disentangle causality, with Miguel et. al. (2004) showing how lower incomes appear to cause conflict with data for African countries. While intuitively plausible, the correlation between low income and conflict has been difficult to explain theoretically since the typical contest model of conflict (that we also employ in section 2 below) shows a positive relation between income and arming, with the latter considered a measure of conflict. Our dynamic model distinguishes between actual conflict and peace under the threat of conflict (in which there is still arming). By doing that, we no longer have to consider arming as a proxy for conflict. More importantly, not only do we find a relationship between income and conflict that is consistent with the empirical evidence but also we find a very plausible mediating mechanism: the incentive to invest more in state capacity for commitments when there is more income at stake. This is consistent with recent findings that weak political systems (proxied by anocracies, but possibly more reflective of young democracies) are more prone to conflict than established political systems and stronger bureaucracies (Fearon and Laitin, 2003, Keefer, 2009).

\section{The basic setting with exogenous state capac- ity}

We begin with a model in which state capacity is fixed. We consider the case of two groups, $A$ and $B$, each contesting a rent (or, income) $Y$ in each period over an indefinite time horizon, with the future discounted under a constant discount factor $\delta$ (which is strictly between 0 and 1). Because we are interested in asking questions about the types and sustainability of peace, we assume that these two groups are identical. This is a reasonable assumption when discussing 
post-conflict peace agreements because it reflects the fact that both agents may have the ability to perpetuate a conflict and that the winner cannot be predicted with any kind of certainty. ${ }^{4}$

Each group $i=A, B$ can produce arms in period $t$, denoted $g_{i t}$, with constant marginal cost. Furthermore, we assume that the payoffs under War and Peace are different, reflected by the superscripts $w$ and $p$. The main differences are that under War, there is destruction, $(1-\phi)$, of a fraction of the rents and the winner gains an advantage in future interactions. For simplicity, we suppose that the winner of conflict receives the rent in all future periods, whereas the loser does not receive anything (for a relaxation of this assumption, see McBride and Skaperdas, 2007). Under Peace a fraction of the rents are protected for both agents by the quality of the institutions they create to regulate and enforce their peace agreement, reflected by a security parameter $\sigma$. We assume $\sigma$ is fixed for now but assume in Section 4 that it can be increased with costly investments.

Under these assumptions, the following single-period $t$ payoff for group $i$ under War is

$$
U_{i t}^{w}\left(g_{A t}, g_{B t}\right)=\frac{g_{i t}}{g_{A t}+g_{B t}} \phi Y-g_{i t},
$$

where $\phi<1$ and $\frac{g_{i t}}{g_{A t}+g_{B t}}$ represents the probability group $i$ wins the conflict. (For an overview of such functions, see section 2 of Garfinkel and Skaperdas, 2007.)

The single-period $t$ payoff for group $i$ under Peace is

$$
U_{i t}^{p}\left(g_{A t}, g_{B t}\right)=\left[\sigma \frac{1}{2}+(1-\sigma) \frac{g_{i t}}{g_{A t}+g_{B t}}\right] Y-g_{i t},
$$

where $0 \leq \sigma \leq 1$. Note that the term in braces represents group $i$ 's share of the rent. Under Peace, the share each side receives depends partly on state capacity and partly on arming. The better the state capacity, the larger the share of rents that are not contestable via threats with arms. When $\sigma$ is close to 0 , arming plays the biggest role in determining the share of each group. When $\sigma$ is close to 1 , arming plays very little role in the share of each side. That

\footnotetext{
${ }^{4}$ Recent works by Chacon, Robinson and Torvik (2006) and Gates and Strom (2007) argue that both conflicts and power-sharing peace agreements are more likely when adversaries are equally matched, because are, in a sense, conflictual relationships whether through violence or other means. Gates and Strom contend that power-sharing agreements between unevenly matched opponents are unsuccessful, resulting in disproportional political power, positive incentives for spoilers and untenable long-term peace solutions.
} 
the contestable portion of group $i$ 's rents depends on how well it would do in a conflict captures how the bargaining outcome under the threat of conflict will depend on the relative strength of each group as measured by arms. ${ }^{5}$

We note that it is typical for peace agreements to have the parties to the agreement maintain their military capacity, either informally - through militias and other forms of military readiness - or formally as part of the agreement. Lebanon, for example, has had quotas for its different confessional groups in the military as well as for its political and administrative offices. In addition to any formal agreements that involve explicit quotas in national armies, different political parties, and administrative or electoral offices, ethnic or religious groups need to maintain militias and keep other resources (arms caches, training grounds, readiness for mobilization and special funds dedicated to them) both as a deterrent and as a bargaining tool. ${ }^{6}$

In a particular period $t$, the two sides make the following decisions:

1. Each side chooses its arming level $g_{i t}$.

2. Given these levels of arming, each side makes a decision whether to accept a Peace agreement or not. If both agree to Peace, then Peace occurs. If one or both choose conflict, then War occurs.

We are interested in knowing when an equilibrium with Peace exists. Specifically, we will show when the highest payoff symmetric Markov Perfect Equilibrium (MPE) with peace exists. ${ }^{7}$ This setting is a dynamic game with three states: A has full power and obtains all the rents without need to arm or bargain with B; B has full power; and both can contest for a share or all of the rents. The first two states can only be reached after a conflict occurs. The setting begins in the third state. A Markov strategy is a Subgame Perfect Equilibrium in which each group chooses a strategy that depends not on the history of play but on the state. With choices only relevant to the third, contestable, state, a Markov strategy tells a player to play a fixed strategy in that state.

\footnotetext{
${ }^{5}$ Anbarci et. al. (2002) show how different bargaining solutions can induce different levels of arming in equilibrium when the utility possibilities frontier is strictly convex.

${ }^{6}$ See, for example, the case studies of power-sharing agreements in Colombia (Gutierrez and Guataqui, 2009) and Lebanon (Salti and Frangie, 2009).

${ }^{7}$ See Fudenberg and Tirole (1996) for a discussion of MPE. MPE are easier to solve than history dependent strategies. Additionally, our setting immediately goes to an abosrbing state after conflict thus precluding history dependent punishment.
} 
Yet before turning to a Peace equilibrium, we first note that there always exists a symmetric MPE with War. Conditional on the other choosing War in step 2, a group's choice between War and Peace is irrelevant because only one side is needed to start conflict, so both choosing War can always be sustained in an MPE. There will thus be a MPE in which each chooses an arming level $g_{W}^{*}$ and War. Given that its opponent chooses this strategy, the value function for group $i$ is

$$
V_{i t}=\frac{g_{i t}}{g_{i t}+g_{W}^{*}}\left[\phi+\frac{\delta}{1-\delta}\right] Y-g_{i t} .
$$

To find the equilibrium $g_{W}^{*}$, we obtain the first order condition of (3) and use symmetry $g_{W}^{*}=g_{i}$ to solve for $g_{W}^{*}$ :

$$
\begin{aligned}
{\left[\frac{1}{g_{i t}+g_{W}^{*}}-\frac{g_{i t}}{\left(g_{i t}+g_{W}^{*}\right)^{2}}\right]\left[\phi+\frac{\delta}{1-\delta}\right] Y-1 } & =0 \Rightarrow \\
\frac{g_{W}^{*}}{\left(g_{W}^{*}+g_{W}^{*}\right)^{2}}\left[\phi+\frac{\delta}{1-\delta}\right] Y & =1 \Rightarrow \\
g_{W}^{*} & =\frac{1}{4}\left[\phi+\frac{\delta}{1-\delta}\right] Y .
\end{aligned}
$$

The MPE has each group choose this $g_{W}^{*}$ and War. Group $i$ 's present discounted payoff in this MPE is

$$
\begin{aligned}
V_{i}^{W} & =\frac{g_{W}^{*}}{g_{W}^{*}+g_{W}^{*}}\left[\phi+\frac{\delta}{1-\delta}\right] Y-g_{W}^{*} \\
& =\frac{1}{4}\left[\phi+\frac{\delta}{1-\delta}\right] Y .
\end{aligned}
$$

We are interested in when an equilibrium with Peace exists. Consider a Markov strategy of this form: "In period $t$ of a contestable state: set $g_{i t}=g_{P}^{*}$ and choose Peace." If each group follows this strategy, then group $i$ 's present discounted payoff is

$$
\begin{aligned}
V_{i t}^{P} & =\frac{1}{1-\delta}\left[\sigma \frac{1}{2}+(1-\sigma) \frac{g_{P}^{*}}{g_{P}^{*}+g_{P}^{*}}\right] Y-\frac{1}{1-\delta} g_{P}^{*} \\
& =\frac{1}{1-\delta} \frac{1}{2} Y-\frac{1}{1-\delta} g_{P}^{*} .
\end{aligned}
$$

Each choosing this strategy will be a MPE (hereafter, equilibrium) when neither group can make a one-shot deviation to achieve a higher payoff. There are three types of one-shot deviation to consider. The first type is to set $g_{i t} \neq g_{P}^{*}$ in step 1 and choose Peace in step 2. The second type is to set $g_{i t}=g_{P}^{*}$ but 
choose War in step 2. The third is to set $g_{i t} \neq g_{P}^{*}$ in step 1 and choose War in step 2 .

A first type deviation will not be made if, conditional on peace, $g_{P}^{*}$ is a Nash equilibrium of the single-period arming game. To find this $g_{P}^{*}$, we obtain the first order condition of $U_{i t}^{p}\left(g_{A t}, g_{B t}\right)$,

$$
\begin{aligned}
(1-\sigma)\left[\frac{1}{g_{A t}+g_{B t}}-\frac{g_{i t}}{\left(g_{A t}+g_{B t}\right)^{2}}\right] Y-1 & =0 \Rightarrow \\
(1-\sigma) \frac{g_{j t}}{\left(g_{A t}+g_{B t}\right)^{2}} Y & =1,
\end{aligned}
$$

and use symmetry $g_{i t}=g_{j t}=g_{P}^{*}$ to obtain

$$
g_{P}^{*}=\frac{1}{4}(1-\sigma) Y .
$$

With this $g_{P}^{*}$ arming level, no first type deviations will be made. From now on, we assume this $g_{P}^{*}$ so that equation (5) becomes

$$
V_{i}^{P}=\frac{1}{1-\delta} \frac{1}{4}(1+\sigma) Y .
$$

A second type deviation will not be made in step 2 if the payoff of choosing Peace exceeds that of choosing War conditional on both having chosen $g_{P}^{*}$ in step 1:

$$
\begin{aligned}
\frac{1}{2} Y+\delta V_{i}^{P} & \geq \frac{1}{2}\left[\phi+\frac{\delta}{1-\delta}\right] Y \Rightarrow \\
\sigma & \geq 1-\frac{2(1-\phi)(1-\delta)}{\delta} \equiv \sigma^{*}
\end{aligned}
$$

This value $\sigma^{*}$ is the minimum level of state capacity required to prevent a second type deviation. Observe that this is more likely to be met when conflict is destructive ( $\phi$ low) and the future is heavily discounted ( $\delta$ low).

Figure 1 illustrates how this critical state capacity level is found. The solid horizontal line denotes the payoff to initiating War given $\phi$ and $\delta$, and the solid upward sloping line is the value to Peace given $\sigma$ and $\delta$. These are, respectively, the right and left hand sides of condition (6). The critical level $\sigma^{*}$ is found where the two lines cross. The War equilibrium exists for all parameter values, but the Peace equilibrium only exists when $\sigma \geq \sigma^{*}$. The dotted horizontal line represents the value to War with destruction parameter $\phi^{\prime}>\phi$. With less 
destruction (higher $\phi$ ), the value to War is increased, and a higher level of state capacity is necessary for Peace to be possible.

A third type deviation will not be made in steps 1 and 2 when $V_{i}^{P}$ is greater or equal to the payoff from the deviation:

$$
\frac{1}{1-\delta} \frac{1}{4}(1+\sigma) Y \geq \max _{g^{\prime}} \frac{g^{\prime}}{g^{\prime}+g_{P}^{*}}\left[\phi+\frac{\delta}{1-\delta}\right] Y-g^{\prime} .
$$

The right hand side $(R H S)$ of this inequality is the highest payoff achievable when choosing $g^{\prime}$ given $g_{P}^{*}$ and War. The left hand side is an increasing linear function of $\sigma$ but does not vary with $\phi$. The right hand side is an increasing function of $\phi$ but does not vary with $\sigma$. Both sides increase in $\delta$. With some work (see Appendix A), it can be shown that (8) is violated under conditions qualitatively similar to those for the first type deviation.

To summarize, we observe that the Peace equilibrium exists, and Peace is more likely to arise, when

(i) state capacity is high ( $\sigma$ high),

(ii) conflict is destructive ( $\phi$ low).

(iii) the future is heavily discounted ( $\delta$ low).

When these three conditions hold, Peace is a self-enforcing arrangement between potential adversaries. Peace is costly to maintain as each side must continue to arm to maintain a bargaining position. However, with the peace arming level $g_{P}^{*}=\frac{1}{4}(1-\sigma) Y$, we observe that the higher the state capacity the fewer the resources devoted to arming. With perfect governance institutions $(\sigma=1)$, the Peace equilibrium achieves an efficient outcome with no resources spent on arming and no resources destroyed by conflict.

That Peace requires low discount factors runs counter to the standard Folk Theorem intuition. However, as McBride and Skaperdas (2007, 2009) explain, this counterintuitive result follows from the dynamic nature of the interaction. Because one group can eliminate its opponent through conflict, engaging in a conflict may be costly today but yield high rewards tomorrow as future resources need not be devoted to arming. ${ }^{8}$

\footnotetext{
${ }^{8}$ McBride and Skaperdas (2009) and Tingley (2009) provide experimental evidence on the negative effect of a longer shadow of the future when there is conflict (but not any investments in conflict management).
} 


\section{On the determinants of commitment and state capacity}

We have seen the critical importance the level of the parameter $\sigma$ has in whether War or Peace prevails. Low levels of the parameter imply that the mechanisms that induce Peace are rather undeveloped and the adversaries need to keep high levels of arming in order to maintain their bargaining power. In turn, this high cost of Peace would lead to War. When the mechanisms for supporting Peace are more developed and the parties can keep lower levels of arming in order to maintain their respective bargaining positions, War is not attractive. What determines, then, the level of governance, security, property rights, or, in short, state capacity, which encourages these commitments to peace? We first briefly discuss some of the possible determinants in general, and then examine the actions that the adversaries might be able to take to improve their ability to commit.

We can conceive of $\sigma$ as a function of accumulated investments, i.e., "capital." The least that is required is the presence of channels of communication and diplomacy between the participants. For higher levels of commitment, rudimentary forms of governance become necessary: mechanisms for making collective decisions and agreements; elementary courts for the adjudication of disputes; security officers for the enforcement of decisions, court rulings, and agreements.

An example of such a rudimentary institution of governance that was agreed upon and paid for by adversaries who were seeking to minimize outright conflict among them is that of the podesta in fourteenth century Genoa (Greif, 1998). The main competing clans - previously engaged in intermittent civil war for decades - agreed to hire every year an outsider, the podesta, along with a limited staff and armed men, who served as administrator and law enforcer but without having enough military capacity to ally himself with one of the clans and expect to defeat the others. Thus, the clans paid for the services of the podesta to maintain a delicate balance of power. They still had to maintain some military readiness but evidently not as much as in the absence of the podesta and with lower risk of warfare.

Whereas many developing countries might still benefit from institutions like that of the podesta, any institutions that allow for greater commitment and less arming on the part of the adversaries would be useful. Predictable and institu- 
tionalized ways of law making increases the commitment power of government that the laws will continue to hold (Keefer, 2009). Building professional police forces, armies, a modern bureaucracy as well as courts are all means for enforcing such laws. ${ }^{9}$ Modern, western versions of these institutions take tremendous resources and time to build and should only be built for their function and not just to mimic form embodied by the modern state. Like the podesta, local institutions, expanded to sustain peace and build credible commitments can lead to future investments and expansion of state capacity. Examples of such institutions include the Conflict Early Warning and Early Response Mechanism (CEWARN) active in pastoral areas of Ethiopia, Kenya, Uganda and Sudan, which serves as a local observer and early warning system to avoid conflict, where publicity acts as a type of enforcement. Likewise, the Gacaca courts of Rwanda can be interpreted as a local investment in state capacity to make credible commitments in post-confict as they provided a local means of settling grievance that was more credible than state institutions. Post-conflict countries and countries at high risk of conflict that do not invest in such institutions must continue arming in order to maintain their respective bargaining positions

We next review the actors and forces that can determine investments in governance.

\section{$3.1 \quad$ Outsiders}

No country is an island when it comes to influences on civil wars and other domestic conflicts. Outsiders - states, international organizations, NGOs, firms, and powerful individuals - typically have direct economic or other interests in the country whereas larger states might have longer-term, geopolitical interests on the political and economic direction a country takes.

The post-World War II collective security arrangements tend to guarantee existing borders. While these arrangements might have reduced the number of interstate wars, the large number of civil wars indicates that collective security norms do not spill over into the domestic arena ${ }^{10}$. With regard to improving

\footnotetext{
${ }^{9}$ The contribution of a modern bureaucracy towards peace and prosperity is not to be overlooked. Research by Przeworski et al (2000) and Keefer (2009) demonstrate that the level of voice and accountability embodied by democratic institutions does not contribute to peace and prosperity so much as the establishment of permanent institutions and bureaucracies that reliably define the "rules of the game".

${ }^{10}$ Indeed, the legacy of international borders defined by the international state system may
} 
domestic security and conflict management, outsiders can be a source of both good and bad influence. ${ }^{11}$ They can be a source of good by providing mediation services and even by nudging the adversaries with sticks and carrots toward solutions that the sides could not come up by themselves. They can provide short-term and long-term assistance with state building, from direct budgetary help to advice on the building of bureaucracy and courts, as well as of the more conventional technical assistance in the building of infrastructure.

Outsiders can be a negative influence when they directly intervene in conflict and even instigate conflict, wittingly or unwittingly. When outside economic interests feel threatened by a government and finance military opposition, even as a bargaining device, the level of trust and ability to commit to future agreements (that is, the level of $\sigma$ ) between the government and its domestic adversaries cannot but deteriorate. Large states with long-term geopolitical interests might want to undermine stability in another large state's backyard of a satellite state and undermine domestic stability there or simply makes sure to fuel continued conflict. Even some actions of the "international community" that are professed to be in the interest of peace and stability could unwittingly, and arguably, undermine stability and peace. ${ }^{12}$

Given that the world has become increasingly globalized economically since World War II, it would be difficult to conceive of internal conflicts in isolation from the rest of the world and the role that outside actors play in either alleviating or exacerbating these conflicts. Yet, there appears to be a dearth of research on the effect of outsiders on the instigation and resolution of conflicts (for example, there is very little recognition of outside factors in civil war, other than some mention of the Cold War, in Collier et. al., 2003).

\subsection{History}

Thinking of conflict management institutions as capital inevitably brings forth the importance of what has occurred in the past between the adversaries in-

contribute to the incidence of civil wars (see Herbst, 2000 and Spears, 2002).

${ }^{11}$ Doyle and Sambanis (2000) find a positive role for UN peacekeeping operations, whereas Sambanis and Schulhofer-Wohl (2005) find evidence of a positive effect of UN peacekeeping operations but no discernible effect on non-UN operations.

${ }^{12}$ Prunier (2009), for example, makes a strong case that a series of actions by Western states and NGOs both prolonged the Rwandan genocide and subsequently unwittingly facilitated the intensification of the wars in the Democratic Republic of the Congo. 
volved in conflict and in the history of the country in general. Very intense and long-lasting conflicts may be intractable ${ }^{13}$. Weak governance in the first place is more likely to lead to conflict. And once conflict begins, whatever little capital of conflict management existed beforehand can quickly depreciate. Bureaucracies, courts, security agencies can deteriorate or stop functioning altogether. Even channels of communication and diplomacy may shut down. Achieving a long-lasting agreement, then, could become ever harder as conflict progresses. Political and governance traditions from the past could help to at least start negotiation. These can vary widely and can include traditional tribal practices of elder gatherings to governance practices inherited from the more recent past of contact with the rest of the world.

\subsection{Investments by the adversaries}

In the end, given whatever capital has been left over from the past and with the help (or hindrance) of outsiders, the adversaries themselves will need to negotiate, structure an agreement, and make sure that it is long-lasting. That is, the parties themselves can be thought of as making investments in conflict management and governance. The actual choices of investment by the parties can be ordinary non-cooperative choices or closer to the socially optimal ones (which are higher than the noncooperative choices.) We next turn to a formal analysis of this problem.

\section{Endogenous determination of state capacity}

As we mentioned earlier the parameter $\sigma$ can be considered a function of the total "capital", $K$, in conflict management and governance, where $\sigma(K)$ denotes the relevant function. $K$ can be broken down into two parts: $K_{-}$, the capital that has been inherited from the past and includes the effects of third parties; and the investments undertaken by the two parties, $I_{A}$ and $I_{B}$. Thus, $\sigma=$ $\sigma\left(I_{A}+I_{B}+K_{-}\right)$. In addition to $\sigma(\cdot)$ being increasing in its argument, we assume that it is strictly concave and differentiable. Furthermore, let $q$ denote the price of these investments to each party.

\footnotetext{
${ }^{13}$ Hartzell and Hoddie (2003) find that more intense conflicts result in less sustainable peace. Cunningham (2006) finds that longer wars produce more spoilers and veto players which further perpetuate conflict.
} 
To keep our analysis simple and the main idea clear, we here suppose that each of the two adversaries can undertake a one-time investment in state capacity capital. After they make their investments simultaneously and publicly, they engage in the interaction studied in Section 2. That is, after making their investments, they then decide how much to arm and whether or not to engage in conflict. As before, conflict occurs if one or both choose it.

Let $\sigma^{*}$ denote the minimum level of state capacity, given the other parameters' values, for which the Peace equilibrium exists. If $\sigma\left(K_{-}\right) \geq \sigma^{*}$, then Peace can be sustained no matter the investments $I_{A}$ and $I_{B}$. The interesting case, and the case which we assume from now on, is when $\sigma\left(K_{-}\right)<\sigma^{*}$.

We again focus on symmetric strategies both before and after investments are made. If investments raise $\sigma\left(I_{A}+I_{B}+K_{-}\right)$above $\sigma^{*}$, then we assume the (symmetric) Peace equilibrium is played thereafter. If $\sigma\left(I_{A}+I_{B}+K_{-}\right)<\sigma^{*}$, then the (symmetric) War equilibrium prevails. Thus, we need to find under what conditions the groups will choose investments that raise the total capital to a level above the threshold $\sigma^{*}{ }^{14}$

Given symmetric coordinated actions after investments, the expected payoff for group $i$ from before investments are made is:

$V_{i}\left(I_{A}, I_{B}\right)=\left\{\begin{array}{cl}\frac{1}{4} \frac{1}{1-\delta}\left(1+\sigma\left(I_{A}+I_{B}+K_{-}\right)\right) Y-q I_{i}, & \text { if } \sigma\left(I_{A}+I_{B}+K_{-}\right) \geq \sigma^{*} \\ \frac{1}{4}\left(\phi+\frac{\delta}{1-\delta}\right) Y-q I_{i} & \text { if } \sigma\left(I_{A}+I_{B}+K_{-}\right)<\sigma^{*} .\end{array}\right.$

Because peace requires a threshold level of state capacity, any investments into state capacity that do not bring $\sigma$ to or above $\sigma^{*}$ will be wasted. It follows that if investments in state capacity cannot bring security to or above the threshold level $\sigma^{*}$, no investment can be expected at all.

As before, a War equilibrium in which each selects $\left(I_{i}=0, g_{W}^{*}\right.$, War $)$ always exists. The strategy of interest to us has each group select $\left(I^{*}, g_{P}^{*}\right.$, Peace $)$ with $\sigma\left(2 I^{*}+K_{-}\right) \geq \sigma^{*}$. Given that the last two in this triplet have been studied above, we need only determine when the investment $I^{*}$ is optimal given the opponent chooses this strategy.

There are two things to consider here: what is the $I^{*}$ that maximizes

\footnotetext{
${ }^{14}$ We ignore here dynamic considerations that migh induce each side to invest looking into building capital for the future even though they would go to War now. A model that has genuine dynamics would be required to allow for that possibility.
} 
the Peace payoff, and is each contributing $I^{*}$ enough to bring state capacity above $\sigma^{*}$. We examine each of these in turn. The first order condition of the $V_{i}\left(I_{A}, I_{B}\right)$ Peace payoff with $I_{A}=I_{B}=I^{*}$ identifies the best investments assuming Peace:

$$
\sigma^{\prime}\left(2 I^{*}+K_{-}\right)=\frac{4 q(1-\delta)}{Y}
$$

If we have

$$
\frac{1}{4} \frac{1}{1-\delta}\left(1+\sigma\left(2 I^{*}+K_{-}\right)\right) Y-q I^{*} \geq \frac{1}{4}\left(\phi+\frac{\delta}{1-\delta}\right) Y,
$$

then the Peace with investment equilibrium exists.

This last condition reveals that high destruction from conflict (low $\phi$ ) makes Peace more likely. It is also worth noting the role of the state capacity function. For investments in Peace to occur, the returns to investment must be sufficiently large. For one, the slope of the state capacity function must be sufficiently high. In particular, if we define $\sigma(\bar{K})=\sigma^{*}$ then it is necessary that

$$
\sigma^{\prime}(\bar{K}) \geq \frac{4 q(1-\delta)}{Y} .
$$

If current investment brings the adversaries right to the threshold capital level, then the adversaries must be willing to maintain (or exceed) those investments. Intuitively, this requires the price of investment $q$ to be sufficiently low, and as in Section 2 the discount factor must be sufficiently low. However, observe that $Y$ must also be sufficiently large. If the rents are too low, then the prize is not worth the investment in state capacity.

We find this last result to be significant. In most models of conflict, a higher prize implies higher arming and worse conflict. Here we also find arming to increase in the size of the prize holding all else constant, yet there are mitigating factors that may swamp out that effect. As income rises, so do the returns to Peace and the returns to investments in the institutions that foster Peace. If the technology exists to create governance institutions, then the rising returns to Peace through investing in institutions may lead adversaries to the bargaining table as $Y$ increases.

However, there are two constraints that might well prevent the implementation of Peace under (9). First, one problem might be the capacity to build $I_{A}^{*}+I_{B}^{*}$, when, as we discussed earlier, modern governing institutions take many years and decades to build. Second, even if the institutions could be built at 
once, it is likely the fiscal capacity of the adversaries would be severely limited and they could contribute only a fraction of the equilibrium level of investment. When obstacles to reaching equilibrium powersharing implied by (9) exist, then there is space for a good-willed outsider to intervene.

Plugging in $I^{*}=\frac{1}{2}\left(K^{*}-K_{-}\right)$into the value function for peace yields

$$
\frac{1}{4} \frac{1}{1-\delta}\left(1+\sigma\left(K^{*}\right)\right) Y-q \frac{1}{2} K^{*}+q \frac{1}{2} K_{-} .
$$

Although a change in $K_{-}$does not change $K^{*}$, it does affect the payoffs of the two groups. Due to the substitutability between $K_{-}$and the adversaries' investments $I_{A}$ and $I_{B}$, an increase in $K_{-}$increases the adversaries' payoffs in the case of Peace because the adversaries need only invest smaller amounts to achieve Peace. This result is illustrated in Figure 2. The upward sloping line is the Peace payoff (12), and the War payoff is the horizontal line. For any $K_{-} \geq \widetilde{K}_{-}$, the adversaries can sustain Peace, but Peace is not sustainable with $K_{-}<\widetilde{K}_{-}$.

Outside forces can help or hinder Peace. By lowering $K_{-}$via actions destructive to state capacity, outside forces can transform a peaceful setting into a conflictual one. By raising $K_{-}$via actions that build local institutions directly or by providing resources conducive to the development of governance institutions, outside forces can help foster peace.

Finally, we observe that the positive externality associated with investment in state capacity will likely yield an underprovision of governance institutions, just as positive externalities lead to underinvestment in public goods in general. When investments for Peace work, the equilibrium will be inefficient. Welfare (in the form of the sum of payoffs) is maximized at $\left(I_{A}, I_{B}\right)=(\widehat{I}, \widehat{I})$ when it solves

$$
\max _{I_{A}, I_{B}} V_{A}\left(I_{A}, I_{B}\right)+V_{B}\left(I_{A}, I_{B}\right) .
$$

In the case of Peace, total welfare equals

$$
\frac{1}{2} \frac{1}{1-\delta}\left(1+\sigma\left(2 \widehat{I}+K_{-}\right)\right) Y-q \widehat{I},
$$

and the level of total capital $\widehat{K}=2 \widehat{I}+K_{-}$that would maximize is implicitly defined by

$$
\sigma^{\prime}(\widehat{K})=\frac{2 q(1-\delta)}{Y}
$$


By comparing (10) and (13) it is clear that $\widehat{I}>I^{*}$ and $\widehat{K}>K^{*}=2 I^{*}+K_{-}$, i.e., the level of security under welfare maximization would be higher than under equilibrium, the amount of arming necessary to maintain Peace would be lower and, of course, payoffs and welfare would be higher.

Obviously, since the optimal level of investment is not an equilibrium, it would be harder to implement in a conflictual environment. Moreover, since there may be any number of challenges to implementing the equilibrium levels of investment (capacity to build, fiscal constraints), the implied optimal levels which are even higher would be very difficult to achieve.

This suggests that wealthier countries should enjoy higher levels of security, at least in the long run when liquidity and capacity constraints are relaxed. External help that can overcome these liquidity and capacity constraints may promote attainment of equilibrium levels of security. It is important to highlight the distinction here between relaxation of liquidity and capacity constraints and substituted capacity from international actors. Relaxation of liquidity and capacity constraints effectively creates the commitment space for adversaries to make their own investments in state capacity. Meanwhile, substituted capacity, as described above, can supplant and even reduce the incentives for actors to invest in their own state capacity, reducing the attainability of sustainable peaceful equilibria.

Both the equilibrium and optimal levels of investment, however, share some similar comparative static results. Using (10) and (13), it can be demonstrated that the respective investment levels are (i) increasing in the contestable income $Y$; (ii) increasing in the discount factor $\delta$; and (iii) decreasing in the price of investments $q$. This suggests that wealthier countries should enjoy higher levels of security, at least in the long run when liquidity and capacity constraints are relaxed. External help that can overcome these liquidity and capacity constraints may promote attainment of equilibrium levels of security.

The effect of the discount factor is the same implied by a folk-theorem argument and contrary to the effect it has on arming effect that we found earlier. Therefore, the shadow of the future can have two countervailing effects. Which effect dominates on arming can be expected to depend on the particular functional form of $\sigma(\cdot)$ and the initial parameters. 


\section{Concluding Remarks}

In this paper we develop a simple model of conflict, allowing actors to invest in state capacity for commitment. We first employ a model in which state capacity is given exogenously to demonstrate what conditions are necessary for war to be an equilibrium solution. The model suggests that states with low capacity where conflict is not very destructive should experience more conflict.

Our model also introduces a channel through which income reduces the likelihood of conflict, namely state capacity. This reconciles theoretical models of conflict which have suggested that when income is high, there should be more conflict as there is more to fight over to the empirical literature in which conflicts are observed with greater frequency in low income countries. When we allow for endogenous investments in state capacity, the model demonstrates how investments for peace by both actors can make peace a stable outcome.

Here we have applied the model to post-conflict states. However, these relationships among elites or other spoilers to peace may exist in any conflictual environment, developing and developed countries alike. This model could be extended to explore exactly how actors have invested in state capacity and avoided conflict, especially for conditions which seem otherwise ripe for civil conflict. The model could be tested empirically using measures of post-conflict institution building and post-conflict demobilization and disarmament - ceteris paribus we would expect peace to last in environments where institutions improve and arming decreases. 


\section{APPENDIX}

\section{A Type Three Deviations with Exogenous $\sigma$}

Suppose $(\sigma=0, \phi=1)$, which implies $g_{P}^{*}=\frac{1}{4} Y$. Our deviation condition of interest can be written as

$$
\begin{aligned}
\frac{1}{1-\delta} \frac{1}{4}(1+\sigma) Y & \geq \max _{x} \frac{x g_{P}^{*}}{x g_{P}^{*}+g_{P}^{*}}\left[\phi+\frac{\delta}{1-\delta}\right] Y-x g_{P}^{*} \Rightarrow \\
\frac{1}{1-\delta} \frac{1}{4}(1+\sigma) Y & \geq \max _{x} \frac{x}{x+1}\left[\phi+\frac{\delta}{1-\delta}\right] Y-x \frac{1}{4}(1-\sigma) Y \Rightarrow \\
\frac{1}{1-\delta} \frac{1}{4} Y & \geq \max _{x} \frac{x}{x+1} \frac{1}{1-\delta} Y-x \frac{1}{4} Y .
\end{aligned}
$$

If there exists an $x$ which violates this condition, then clearly there is an optimal $x$ that violates the condition. So consider:

$$
\begin{aligned}
\frac{1}{1-\delta} \frac{1}{4} Y & <\frac{x}{x+1} \frac{1}{1-\delta} Y-x \frac{1}{4} Y \Rightarrow \\
1-\frac{4}{x+1}+\frac{1}{x} & <\delta .
\end{aligned}
$$

Thus, with $(\sigma=0, \phi=1)$ and $\delta$ sufficiently large, there is an $x$ that violates the condition.

Now suppose $(\sigma=1, \phi=0)$, which implies $g_{P}^{*}=0$. The RHS of the deviation condition is maximized by setting $g^{\prime}=\epsilon>0$ small. This yields deviation condition

$$
\begin{aligned}
\frac{1}{1-\delta} \frac{1}{2} Y & \geq \frac{\delta}{1-\delta} Y-\epsilon \Rightarrow \\
\frac{\frac{1}{2} Y+\epsilon}{Y+\epsilon} & \geq \delta .
\end{aligned}
$$

Thus, with $(\sigma=1, \phi=0)$ and $\delta$ sufficiently small, the condition is satisfied.

Applying continuity and the intermediate value theorem, there must be a $\left(\sigma^{* *}, \phi^{* *}, \delta^{* *}\right)$, such that the deviation condition is satisfied and the Peace equilibrium exists when $\sigma \geq \sigma^{* *}, \phi \leq \phi^{* *}$, and $\delta \leq \delta^{* *}$. 


\section{REFERENCES}

Anbarci, N., S. Skaperdas, and C. Syropoulos, C. (2002), Comparing bargaining solutions in the shadow of conflict: How norms against threats can have real effects, Journal of Economic Theory 106:1-16.

Blattman, Christopher and Edward Miguel, (2009), "Civil War," forthcoming, Journal of Economic Literature.

Chacon, Mario, James A. Robinson and Ragnar Torvik (2006) "When is Democracy an Equilibrium? Theory and Evidence from Colombia's La Violencia" CEPR Discussion Paper 5679.

Collier, P., V.L. Elliott, H. Hegre, A. Hoeffler, M. Reynal-Querol, N. Sambanis (2003), Breaking the Conflict Trap; Civil War and Development Policy, World Bank Policy Report (Washington, DC: World Bank and Oxford University Press).

Cunningham, David E. (2006) "Veto Players and Civil War Duration" American Journal of Political Science, 50 (4).

Doyle, Michael and Nicholas Sambanis (2000), "International Peacebuilding: A Theoretical and Quantitative Analysis," American Politican Science Review, December, 94(4), 779-801.

Fearon, James, "Rationalist Explanations for War," International Organization,1995, 49(3), 379-414.

Fudenberg, Drew and Jean Tirole (1996), Game Theory, MIT Press.

Garfinkel, Michelle R. and Stergios Skaperdas (2000), "Conflict without misperceptions or incomplete information: how the future matters," Journal of Conflict Resolution 44:793-807.

Garfinkel, Michelle R. and Stergios Skaperdas, (2007), "Economics of Conflict: An Overview," in T. Sandler and K. Hartley (eds.), Handbook of Defense Economics, Vol. II, 649-709.

Genicot, Garance and S. Skaperdas (2002), Investing in conflict management, Journal of Conflict Resolution 46:154-170.

Greif, A. (1998), Self-enforcing Political Systems and Economic Growth: Late Medieval Genoa," in R. Bates, A. Greif, M. Levi, and J-L. Rosenthal, Analytic Narratives, Princeton: Princeton University Press.

Gutierrez Sanin, Francisco and Juan Carlos Guaraqui (2009), "The Colombian case: Peace-Making and Power Sharing: The National Front (1958-1974) 
and New Constitution (1991-2002) experiences," May.

Hartzell, Caroline and Matthew Hoddie (2003) "Institutionalizing Peace: Power Sharing and Post-Civil War Conflict Management" American Journal of Political Science, 47 (2).

Herbst, Jeffrey (2000), States and Power in Africa, Princeton: Princeton University Press.

Hirshleifer, Jack, Theorizing about conflict, in K. Hartley and T. Sandler, eds., Handbook of Defense Economics, Vol.1, 165-189, 1995, New York: Elsevier.

Hoddie, Matthew and Caroline Hartzell (2003) "Civil War Settlements and the Implementation of Military Power-Sharing Arrangements" Journal of Peace Research, 40 (3).

Jarstad, Anna K. and Desiree Nilsson (2008) "From Words to Deeds: The Implementation of Power-Sharing Pacts in Peace Accords" Conflict Management and Peace Science, 25 (3).

Kumar, Vimal, (2008), On the Dynamics of Property Rights, Ph.D. dissertation, Department of Economics, University of California, Irvine.

McBride, Michael and Stergios Skaperdas (2007) "Explaining Conflict in Low-Income Countries: Incomplete Contracting in the Shadow of the Future," in M. Gradstein and K.A. Konrad, (eds.), Institutions and Norms in Economic Development, 141-161, Cambridge, MA: MIT Press.

McBride, Michael and Stergios Skaperdas (2009) "Conflict, Settlement, and the Shadow of the Future," May, Working paper.

Miguel, Edward, Shanker Satyanath and Ernest Sergenti (2009) "Economic Shocks and Civil Conflict: An Instrumental Variables Approach," Journal of Political Economy, 11294), 725-753.

Powell, Robert (2006), "War as a Commitment Problem," International Organization, 60, 169-203.

Prunier, Gerard, 2009. Africa's World War: Congo, the Rwandan Genocide, and the Making of a Continental Catastrophe. Oxford University Press.

Przeworski, Adam, Michael E. Alvarez, Jose Antonio Cheibub and Fernando Limongi (2000) Democracy and Development: Political Institutions and WellBeing in the World, 1950-1990, Cambridge: Cambridge University Press.

Salti, Nisreen and Samer Frangie (2009), "Lebanon Case Study, Collaborative research project on "Peace and Development," World Bank, May. 
Sambanis, Nicholas and Jonah Schulhofer-Wohl (2005), "Evaluating Multilateral Interventions in Civil Wars: A Comparison of UN and Non-UN Peace Operations," December, Yale University.

Skaperdas, Stergios (2006), "Bargaining versus Fighting," Defence and Peace Economics, December, 17(6), 657-676.

Spears, Ian S. (2002) "Africa: The Limits of Power-Sharing" Journal of Democracy 13 (3).

Tingley, Dustin H. (2009) "The Dark Side of the Future: An Experimental Test of Commitment Problems in Bargaining," manuscript, Princeton University, Department of Political Science.

Werner, Suzanne and Amy Yen (2005) "Making and Keeping Peace" International Organization, 59. 
Figure 1: Value Functions for War and Peace with Exogenous $\sigma$

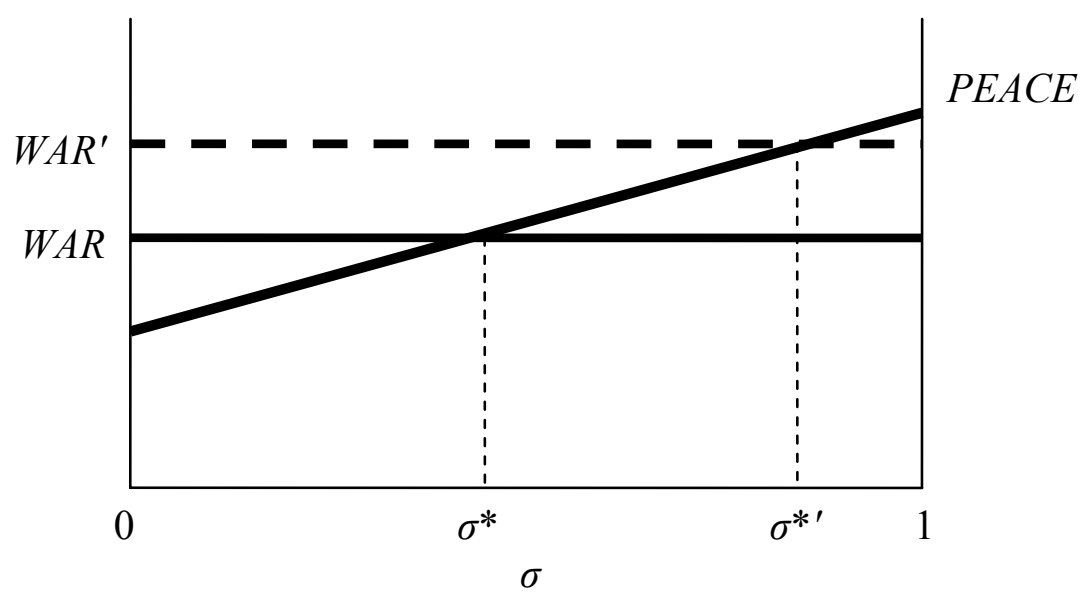

Figure 2: Value Functions for War and Peace with Endogenous $\sigma$

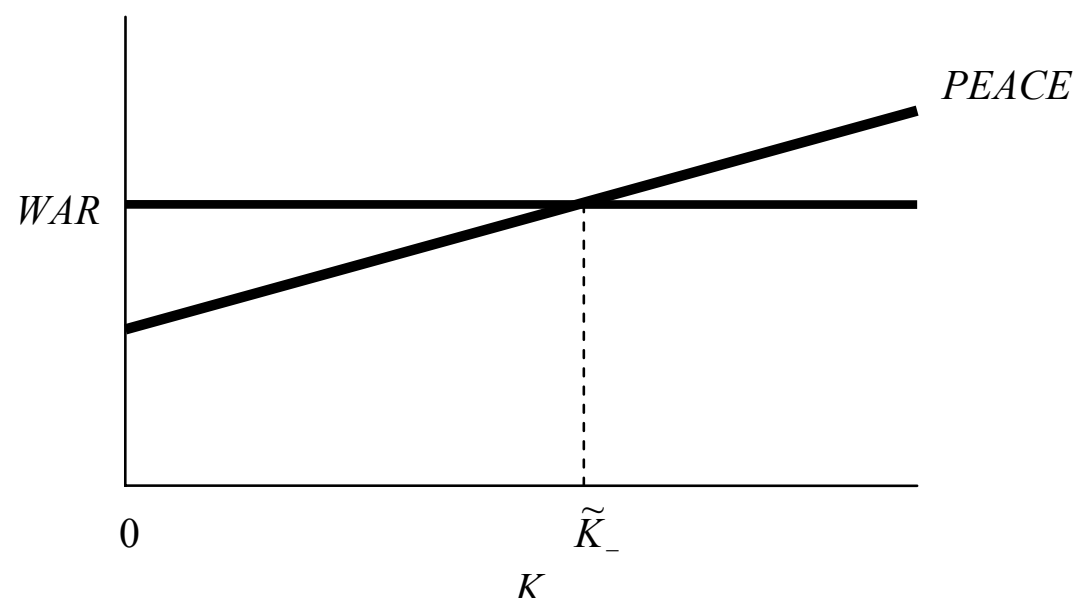

